Johns, A. T. (1951). J. gen. Microbiol. 5, 326-336.

\title{
The Mechanism of Propionic Acid Formation by Veillonella gazogenes
}

\author{
By A. T. JOHNS* \\ Biochemistry Department and Agricultural Research Council Unit of Animal \\ Physiology, University of Cambridge
}

SUMMARY : The mechanism of propionic acid formation from lactate by Veillonella gazogenes is according to the scheme:

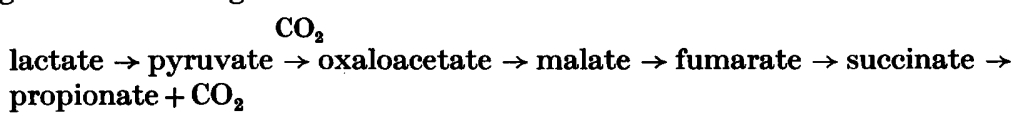

The evidence for this scheme is: $(a)$ Washed suspensions of the organism grown on lactate attack, under anaerobic conditions, pyruvate, oxalacetate, L-malate, fumarate and succinate, but not D-tartrate. (b) Organisms grown on D-tartrate attack it and all the substances listed in (a) except lactate. (c) Succinic acid is quantitatively decarboxylated to propionic acid and carbon dioxide. $(d)$ The amount of propionic acid produced from lactate is influenced by the $\mathrm{CO}_{2}$ concentration in the medium. (e) $\mathrm{CO}_{2}$ is fixed in the carboxyl group of propionic acid during fermentation of lactate.

In a previous paper (Johns, 1951) the isolation of a strictly anaerobic micrococcus from the rumen of sheep was described. It was identified as Veillonella gazogenes and the products of its fermentation of lactate shown to be propionic and acetic acids, carbon dioxide and hydrogen. Unlike Propionibacterium it does not ferment sugars or form succinic acid as an end product.

The mechanism of propionic acid formation, which has been studied only in Propionibacterium has remained uncertain (Werkman \& Wood, 1942; Krebs \& Eggleston, 1941). Since lactate and pyruvate are readily converted to propionate by these bacteria it has been assumed that lactate is an intermediate in the reduction of pyruvate to propionate as follows:

$$
\mathrm{CH}_{3} \cdot \mathrm{CO} . \mathrm{COOH} \stackrel{2 \mathrm{H}}{\rightarrow} \mathrm{CH}_{3} \cdot \mathrm{CHOH} . \mathrm{COOH} \stackrel{2 \mathrm{H}}{\rightarrow} \mathrm{CH}_{3} \cdot \mathrm{CH}_{2} \cdot \mathrm{COOH}+\mathrm{H}_{2} \mathrm{O} .
$$

Barker \& Lipmann (1944), using dried cells of $P$. pentosaceum, ruled out this possibility by showing that, in the presence of sodium fluoride, lactate reduction could be completely blocked with only $57 \%$ inhibition of pyruvate fermentation. Moreover, when the lactate reduction was blocked, no accumulation of lactate occurred when pyruvate was fermented.

The experiments of Carson \& Ruben (1940) and of Wood, Werkman, Hemingway \& Nier (1940) with isotopic carbon showed that propionic acid formed in the fermentation of glycerol by Propionibacterium contained fixed carbon dioxide. Wood, Werkman, Hemingway \& Nier (1941) found this fixed carbon to be exclusively in the carboxyl group of the propionate, and also in the carboxyl groups of succinate. The quantitative results indicated that the most likely mechanism for propionic acid production was by decarboxylation

* Present address: Plant Chemistry Laboratory, Palmerston North, New Zealand. 
of succinic acid. However, Werkman \& Wood (1942) stated 'There is some evidence that propionic acid bacteria can decarboxylate succinate anaerobically but it is questionable whether or not the rate of this reaction is high enough to be of any considerable importance.' A number of workers have been unable to demonstrate any decarboxylation of succinate. The discovery that Veillonella gazogenes produces propionic acid offered an opportunity for the investigation of this problem in another bacterial species.

\section{EXPERIMENTAL}

\section{Methods}

A strain of $V$. gazogenes isolated from the rumen of sheep was studied. The methods used in this work were as previously described (Johns, 1951) with the addition that washed suspensions of $V$. gazogenes were prepared and their metabolism studied by the Warburg technique. Bacteria were grown in litre flasks on the same medium as used for their isolation, with the addition of sodium sulphide to $0.01 \%(\mathrm{w} / \mathrm{v})$. Good growth was obtained in 12-18 hr.

The preparation of active washed suspensions of the bacteria was best accomplished by centrifuging down the cells and washing them with boiled distilled water containing $0.01 \%(w / v)$ sodium sulphide. Much less active suspensions were obtained when glutathione was used as reducing agent. The $\mathbf{Q}_{\mathrm{Co}_{\mathbf{2}}}$ found with succinate as substrate was at least ten times greater in the presence of $0.01 \% \mathrm{Na}_{2} \mathrm{~S}$ than in its absence.

Pyruvic acid was estimated manometrically by the carboxylase method of Westerkamp (1933) as modified by Krebs \& Johnson (1937).

Dry weights of bacteria in suspensions were determined by means of a photoelectric turbidimeter which had been calibrated against suspensions containing known dry weights of bacteria. In expressing the rate of a fermentation the conventional quotient ' $Q$ ' for gas production is employed. $\boldsymbol{Q}_{\mathrm{Co}_{2}}$ is defined as $\mu \mathrm{l}$. $\mathrm{CO}_{2} / \mathrm{mg}$. dry-weight bacteria $/ \mathrm{hr}$.

Preparation of $\mathrm{Na}_{2} \mathrm{C}^{13} \mathrm{O}_{3} . \mathrm{KC}^{13} \mathrm{~N}$ (18.8 atoms \% excess) was converted to barium carbonate by combustion in the Pregl microcombustion apparatus and the $\mathrm{CO}_{2}$ absorbed in saturated barium hydroxide. The precipitated barium carbonate was centrifuged down and carefully washed. The labelled carbon dioxide was then released by addition of acid in an evacuated vessel and absorbed in sodium hydroxide, thus yielding sodium carbonate containing isotopic carbon.

Carbon dioxide fixation experiment with $\mathrm{C}^{13} \mathrm{O}_{2}$. A growth experiment with Veillonella was carried out in a sealed tube. The inorganic medium $+1.5 \mathrm{ml}$. sodium lactate $(0.3 \mathrm{~g} . / \mathrm{ml}$.) $+\mathbf{0 . 4} \%$ Difco yeast extract was adjusted to such a $\mathrm{pH}$ value that on the addition of $2 \mathrm{ml}$. of $\mathrm{N}-\mathrm{Na}_{2} \mathrm{CO}_{3}$ the final $\mathrm{pH}$ was 7 . The medium was autoclaved in the tube closed by a cotton-wool plug and the enriched $\mathbf{C}^{\mathbf{1 3}}$ carbonate autoclaved separately. Before inoculation the labelled sodium carbonate was added to the medium. After inoculation from a $24 \mathrm{hr}$. culture of Veillonella, the cotton-wool plug was pushed down in the tube which was sealed off above the plug. Thus, as the fermentation proceeded, the gas 
produced was under pressure. As it had been shown previously that the amount of propionic acid formed was dependent on the partial pressure of $\mathrm{CO}_{2}$ it was thought that, by having the gas under pressure, a greater proportion of propionic acid would be formed and the fixation of $\mathrm{CO}_{2}$, if any, would be more convincingly demonstrated. A control fermentation in which no carbonate was added and the tube left unsealed was inoculated at the same time.

When the fermentation was completed, the volatile acids were distilled off, separated on a partition chromatogram and finally isolated as barium salts. To determine the total $\mathrm{C}^{13}$ in the acetic and propionic acids these barium salts were combusted in the Pregl micro-combustion apparatus and the carbon dioxide produced absorbed in barium hydroxide. The barium carbonate was dried for assay.

To determine the $\mathrm{C}^{13}$ concentration in the carboxyl group of the propionic acid, advantage was taken of the fact that when barium salts of lower fatty acids are heated at a sufficiently high temperature the corresponding ketone and carbon dioxide are produced, the carbon dioxide coming solely from the carboxyl group. In the dry distillation of barium propionate, for example, diethylketone and carbonate are formed:

$$
\left(\mathrm{CH}_{3} \mathrm{CH}_{2} \mathrm{CO}_{2}\right)_{2} \mathrm{Ba} \rightarrow\left(\mathrm{CH}_{3} \mathrm{CH}_{2}\right)_{2} \mathrm{CO}+\mathrm{BaCO}_{3} \text {. }
$$

According to the accepted mechanism of the reaction $50 \%$ of the carboxyl carbon should be in the carbonate and the other $50 \%$ in the ketone. This distribution of carboxyl carbon was confirmed by Wood, Werkman, Hemingway, Nier \& Stuckwisch (1941) who used synthetic propionic acid labelled in the carboxyl group. They found that the reaction proceeded quantitatively at $460^{\circ}$.

A sample of barium propionate produced from the Veillonella fermentation was heated to $460^{\circ}$, the diethylketone driven off and the carbon dioxide liberated from the barium carbonate that remained and absorbed in barium hydroxide. The resulting barium carbonate was washed and dried. The samples of barium carbonate were assayed with the mass spectrograph for $\mathrm{C}^{\mathbf{1 3}}$ excess over the normal ratio of $\mathrm{C}^{13} / \mathrm{C}^{12}$ of $0 \cdot 0109$.

\section{RESULTS}

\section{Succinic acid decarboxylation}

To test whether Veillonella decarboxylated succinate, washed suspensions suspended in $0.1 \mathrm{M}$ phosphate buffer ( $\mathrm{pH} 6 \cdot 8$ ) were used and the manometers gassed with nitrogen (oxygen-free) and equilibrated at $37^{\circ}$. On tipping sodium succinate from the side bulb a rapid evolution of gas took place.

A balance experiment was carried out under the same conditions to identify the products formed. Gas production was measured with manometers and a large-scale fermentation was carried out in duplicate in Krebs vessels with the same proportions of constituents as in the manometers. Carbon dioxide was identified by using $20 \% \mathrm{NaOH}$ in the centre well of the manometer flasks. In the flasks where the $\mathrm{CO}_{2}$ was absorbed it was shown that reaction had taken place by distilling $1 \mathrm{ml}$. of the liquid in a Markham steam distillation apparatus, collecting $30 \mathrm{ml}$. of distillate, and titrating the total volatile acid. 
The propionic acid from the Krebs vessels was identified by its rate of movement down a silica gel chromatographic column and compared with that of a mixture of known acids. Only one band appeared as the product of the reaction, its identity being confirmed by adding pure propionic acid and observing that with this mixture again only one band appeared on the chromatogram. The results of a typical experiment are shown in Table 1 . The theoretical figures given in Table 1 are calculated for the reaction:

$$
\text { HOOC. } \mathrm{CH}_{2} \cdot \mathrm{CH}_{2} \cdot \mathrm{COOH} \rightarrow \mathrm{CH}_{3} \cdot \mathrm{CH}_{2} \cdot \mathrm{COOH}+\mathrm{CO}_{2} \text {. }
$$

The results are seen to agree very well with this equation.

\section{Table 1. Products of the decarboxylation of sodium succinate by washed suspensions of Veillonella}

Gas production measured in Warburg manometers containing $1 \cdot 1 \mathrm{ml}$. 0.1 $\mathrm{m}$ phosphate buffer (pH 6.8) $0.2 \mathrm{ml}$. $2 \mathrm{~N}-\mathrm{H}_{2} \mathrm{SO}_{4} ; 1 \mathrm{ml}$. bacterial suspension (24 mg. dry-wt. bacteria); $0.2 \mathrm{ml} .0 \cdot 1 \mathrm{~m}$ succinate.

Acid formation determined in Krebs vessels using same proportion of constituents. Temp. 37 ${ }^{\circ}$.

(a) Gas production

(b) Acid production
Products $\left(\mu \mathrm{l} . \mathrm{CO}_{2}\right)$

445, 440

Theoretical*

$0 \cdot 2 \mathrm{ml} .0 \cdot 1 \mathrm{~m}$ succinate

mmol. propionic acid

$0.505,0.51 \quad 0.5$

It was found that washed suspensions of the bacteria did not attack malonate, nor did malonate up to $0.01 \mathrm{~m}$ inhibit the decarboxylation of succinic acid.

The $\mathrm{pH}$ optimum for the decarboxylation reaction was determined using 0.1 M phosphate buffer at different $\mathrm{pH}$ values (checked by the glass electrode). The curve obtained by plotting $\mu \mathrm{l} . \mathrm{CO}_{2}$ produced in $5 \mathrm{~min}$. against $\mathrm{pH}$ is shown in Fig. 1. The $\mathrm{pH}$ optimum of the decarboxylation reaction was between 5.9 and 6.0 , with a $\mathbf{Q}_{\mathrm{CO}_{2}}$ of 280 . This is of the same order of activity as Gale's amino-acid decarboxylases with similar $\mathrm{pH}$ optima (Gale, 1946). Attempts to obtain a cell-free extract of the bacteria which should be active in the decarboxylation of succinic acid were unsuccessful.

\section{Fermentation of possible intermediates in propionic acid formation}

The action of washed suspensions on other possible intermediates in the formation of propionic acid was tested; these intermediates included malic, fumaric, oxaloacetic and pyruvic acids (Krebs \& Eggleston, 1941). The manometric technique was used and the production of hydrogen looked for by the use of $\mathrm{CO}_{2}$ absorbers in the centre well of the manometer flask. In all cases there was a rapid decomposition of substrate as shown by the production of gas. Only the L-isomer of malic acid was attacked.

Balance experiments were carried out with L-malate, fumarate and pyruvate as substrates. Table 2 shows the results obtained. The redox index was calculated by the method of Johnson, Peterson \& Fred (1931). With pyruvate under 
Table 2. Products obtained from various possible intermediates in propionic acid formation by Veillonella, using washed suspensions

Gas production measured in Warburg manometers and acid formation in Krebs vessels using the same proportion of constituents. Temp. $37^{\circ}$. Results expressed as mmol. $/ 100 \mathrm{mmol}$. substrate.

Fermentation products (mmol./100 mmol. substrate)

\begin{tabular}{|c|c|c|c|c|c|c|}
\hline \multirow[b]{2}{*}{ Substrate } & & \multirow{2}{*}{$\begin{array}{c}\text { Carbon } \\
\text { recovery } \\
(\%)\end{array}$} & \multirow[b]{2}{*}{$\begin{array}{c}\text { Redox } \\
\text { index }\end{array}$} \\
\hline & $\begin{array}{l}\text { Propionic } \\
\text { acid }\end{array}$ & $\begin{array}{l}\text { Acetic } \\
\text { acid }\end{array}$ & $\mathrm{CO}_{2}$ & $\mathbf{H}_{2}$ & & \\
\hline Pyruvate & $5 \cdot 0$ & 97 & 94 & 94 & 106 & 1.00 \\
\hline L-malate & 62 & 32 & 150 & 32 & 100 & $1 \cdot 02$ \\
\hline Fumarate & 66 & 31 & 152 & 31 & 103 & 1.03 \\
\hline Succinate & 101 & - & 98 & - & 100 & $1 \cdot 06$ \\
\hline
\end{tabular}

the conditions used the reaction was almost entirely a dissimilation of pyruvate into acetic acid, carbon dioxide and hydrogen, with only a small amount of propionic acid. As malate and fumarate are at the same level of oxidation it is to be expected that they would produce the products of fermentation in the same relative proportions. It was found that organisms grown on lactate as substrate did not attack D-tartrate in washed suspension. However, when Veillonella was grown on D-tartrate the washed suspension attacked D-tartaric acid with great vigour, the $Q_{\mathrm{CO}_{2}}$ being 400 . This is illustrated in Fig. 2.

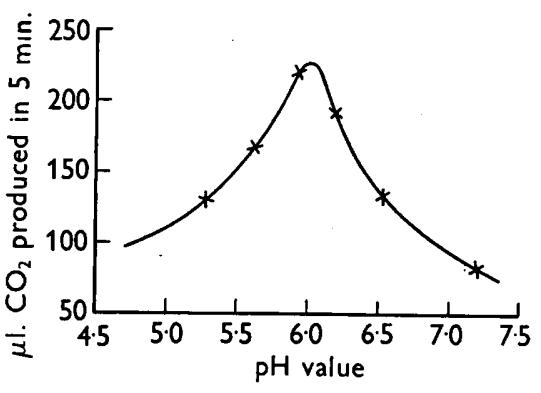

Fig. 1

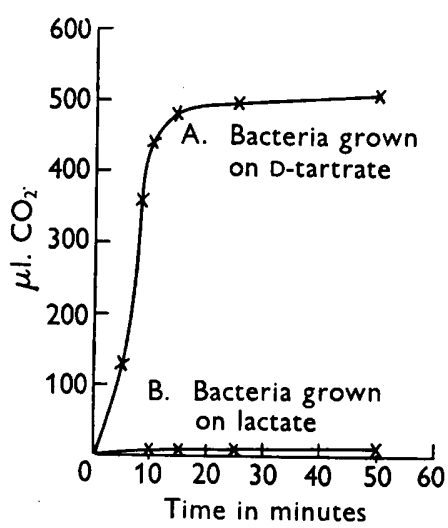

Fig. 2

Fig. 1. The decarboxylation of succinic acid by Veillonella gazogenes of various pH values. $V$.gazogenes $10 \mathrm{mg}$. dry-wt./vessel; $0 \cdot 1 \mathrm{M}$ phosphate buffer, $0.2 \mathrm{ml}$.; $2 \mathrm{~N}-\mathrm{H}_{2} \mathrm{SO}_{4}, 0.2 \mathrm{ml}$.; $0.1 \mathrm{M}$ succinate. Temp. $36^{\circ}$. Duplicate manometers, in one, acid tip at beginning; in the other, acid tip after $5 \mathrm{~min}$.

Fig. 2. Action on D-tartrate of washed suspensions of $V$. gazogenes grown (A) in presence of $D$ tartrate, (B) in presence of lactate. Equal dry-weight $/ \mathrm{ml}$. of bacterial suspension used; $0.2 \mathrm{ml}$. 0.1 $\mathrm{m}$ substrate; 0.1 M phosphate buffer ( $\mathrm{pH} \mathrm{5.8}$ ); temperature $37^{\circ}$.

It was also found that organisms grown on D-tartrate quantitatively decarboxylated succinic acid and dissimilated pyruvate, oxaloacetate, L-malic and fumaric acids, but not lactate. The enzymes responsible for the fermentation of $\mathbf{D}$-tartaric acid were thus adaptive, whereas those responsible for the dissimilation of oxaloacetic, L-malic, fumaric and succinic were constitutive. 


\section{Effect of an atmosphere of hydrogen on gas production}

Cardon \& Barker (1947) isolated an organism, Diplococcus glycinophilus, which formed acetic acid, carbon dioxide and hydrogen from glycine. They found that the amount of hydrogen produced depended on the partial pressure of hydrogen in the gas phase; in an atmosphere containing more than $25 \%$ hydrogen, no hydrogen accumulated. Also Kubowitz (1934) found that the production of acetic acid, butyric acid, carbon dioxide and hydrogen in glucose fermentation by Clostridium butylicum was inhibited by hydrogen, lactic acid being formed instead.

To see whether an atmosphere of hydrogen made any difference to the amount of gas produced from pyruvate by Veillonella an experiment was run in which one set of manometers was filled with nitrogen and a duplicate set filled with hydrogen. The hydrogen production was determined with $20 \%$ $\mathrm{NaOH}$ in the centre well of the manometer cups. Though hydrogen production was slightly less in an atmosphere of hydrogen the difference was hardly significant when compared with the major effects noted by Kubowitz (1934), and by Cardon \& Barker (1947). The washed suspensions of Veillonella were inactive against sodium formate, indicating that hydrogen production was not via formic acid.

Hydrogenase. Experiments with washed suspensions in Thunberg tubes showed that methylene blue was rapidly decolorized in an atmosphere of hydrogen, indicating the presence of hydrogenase in the bacteria.

\section{Pyruvate dissimilation}

The optimum $\mathrm{pH}$ for the fermentation of sodium pyruvate was determined in Warburg manometers by measuring the hydrogen production at various $\mathrm{pH}$ values in $0 \cdot 1 \mathrm{~m}$ phosphate buffer, $\mathrm{CO}_{2}$ being absorbed by $20 \% \mathrm{NaOH}$. As will be seen from Fig. 3 the $\mathrm{pH}$ optimum was about 6.2 and the $Q_{\mathrm{H}_{2}}=114$. This $\mathrm{pH}$ optimum is considerably higher than that found for the fermentation of pyruvate by Propionibacterium (Barker \& Lipmann, 1944). Woods \& Clifton (1937) found a $Q_{\mathrm{H}_{2}}$ of 25-30 for hydrogen production by Clostridium tetanomorphum from pyruvate.

\section{Fermentation of lactate by washed suspensions}

Washed suspensions prepared by the method described above were often only feebly active against lactate. In a typical experiment $512 \mu \mathrm{l}$. of gas were formed from $0.2 \mathrm{ml}$. of $0.06 \mathrm{M}$ pyruvate in $60 \mathrm{~min}$. compared with $5 \mu \mathrm{l}$. from $0.2 \mathrm{ml}$. of $0.1 \mathrm{M}$ lactate in the same period.

Generally it was found that the fermentation of lactate proceeded much better in bicarbonate buffer and an atmosphere of $\mathrm{CO}_{2}$ than in phosphate buffer at the same $\mathrm{pH}$ and an atmosphere of nitrogen. On several occasions when there was no activity against lactate with washed suspensions in phosphate buffer, the reaction proceeded in bicarbonate. A typical result is shown in Fig. 4. 
Fumarate was added in catalytic amounts $(100 \mu \mathrm{g}$./vessel) to see whether it would act as a hydrogen acceptor and initiate the reaction. In flasks in which $\mathrm{CO}_{2}$ was absorbed there was only a slight evolution of hydrogen which soon ceased; the reaction proceeded satisfactorily, however, in flasks which had no $\mathrm{NaOH}$ in the centre well and therefore $\mathrm{CO}_{2}$ in the gas phase.

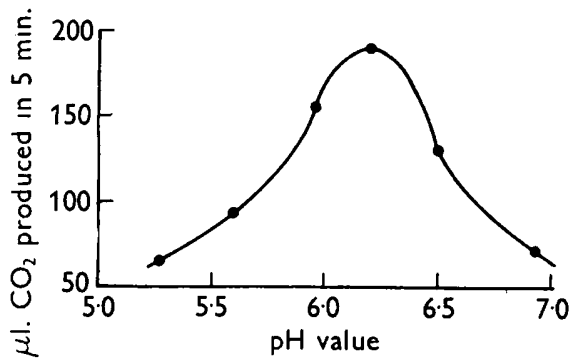

Fig. 3

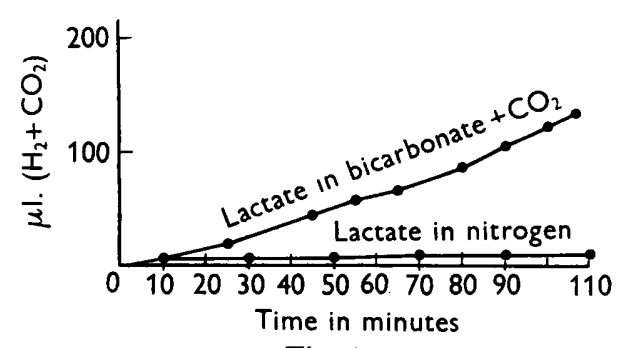

Fig. 4

Fig. 3. The rate of pyruvate dissimilation by washed suspensions of Veillonella as measured by $\mathrm{H}_{2}$ production, at different $\mathrm{pH}$ values.

Fig. 4. The effect of the presence and absence of $\mathrm{CO}_{2}$ on the rate of dissimilation of lactate by washed suspensions of Veillonella. The manometers gassed with nitrogen contained phosphate buffer at the same $\mathrm{pH}$ as the bicarbonate, $\mathrm{pH} 6 \cdot 8$.

\section{Effect of $\mathrm{CO}_{2}$ concentration on fermentation of lactate}

As Elsden (1938) had shown with Escherichia coli that the amount of succinic acid formed in fermentation of pyruvate, glucose and galactose was altered by the carbon dioxide concentration in the medium, it was thought that if propionic acid were formed via decarboxylation of succinic acid, the $\mathrm{CO}_{2}$ concentration should influence the amount of propionic acid formed.

To test this three Krebs vessels were shaken in a water-bath at $\mathbf{3 7}^{\circ}$; each vessel contained the same volume of liquid, sodium lactate solution, washed suspension of bacteria, and were all at $\mathrm{pH} 6 \cdot 8$. Vessel 1 contained $0 \cdot 1 \mathrm{~m}$ phosphate buffer and nitrogen $\left(\mathrm{CO}_{2}\right.$ and oxygen free) was bubbled through the medium continuously during incubation to remove $\mathrm{CO}_{2}$ as it was formed. Vessel 2 contained $0.1 \mathrm{M}$ phosphate buffer and was gassed with nitrogen at the start of the experiment but not during it, so that any $\mathrm{CO}_{2}$ produced could accumulate. Vessel 3 contained bicarbonate buffer at $\mathrm{pH} \mathrm{6.8} \mathrm{through} \mathrm{which}$ $\mathrm{CO}_{2}$ (oxygen-free) was bubbled continuously during the fermentation. The vessels were thoroughly gassed with their respective gases before the substrate was added. The result was that while no lactate in vessel 1 disappeared, in vessels 2 and 3 all the lactate was utilized and the following propionic:acetic acid ratios were obtained, namely in vessel 2, 1.21:1 and in vessel 3, 2:1. From these results it will be seen that the manometric experiments with lactate in which $\mathrm{CO}_{2}$ was absorbed were verified, i.e. fermentation did not take place in the absence of $\mathrm{CO}_{2}$, and that the amount of propionic acid formed was dependent on the carbon $\mathrm{CO}_{2}$ concentration in the medium. The experiment was repeated several times and in no case did fermentation occur when $\mathrm{CO}_{2}$ - 
free nitrogen was bubbled vigorously through the fermentation liquid. The results indicated fairly strongly that formation of propionic acid follows the scheme proposed by Carson, Foster, Ruben \& Barker (1941) and by Krebs \& Eggleston (1941) for the formation of succinic acid, with the addition that propionic acid is formed by decarboxylation of succinic acid (see Fig. 5).

The further evidence which seemed desirable to justify this hypothesis appeared to be the demonstration of $\mathrm{CO}_{2}$ fixation, and the location of the fixed carbon in the carboxyl group of the propionic acid formed. It was felt that the most satisfactory way to show $\mathrm{CO}_{2}$ fixation in propionic acid would be by a growth experiment in the presence of $\mathrm{Na}_{2} \mathrm{C}^{13} \mathrm{O}_{3}$ with sodium lactate as sub-

Table 3. Results of $\mathrm{C}^{13}$ assay with mass spectrograph of acetic and propionic acids produced in Veillonella fermentation of lactate in the presence of $\mathrm{C}^{13}$ enriched sodium carbonate

Each result is the arithmetic mean of at least ten determinations.

$\quad$ Sample
Cylinder $\mathrm{CO}_{2}$
Acetic acid
Cylinder $\mathrm{CO}_{2}$
Total propionic acid
Cylinder $\mathrm{CO}_{2}$
Carboxyl of propionic acid

Atoms $\%$
$\mathbf{C} 13$
$1 \cdot 10$
$1 \cdot 11$
$1 \cdot 10$
$1 \cdot 78$
$1 \cdot 10$
$2 \cdot 75$

Atoms \%
excess C13
-
$\begin{gathered}0.01 \\ - \\ 0.68 \\ -\end{gathered}$

strate. The results are given in Table 3. The 0.01 atom percentage excess in the acetic acid is not regarded as significant. The chromatographic method does not give complete separation of the bands (Barker \& Wikén, 1948).<smiles>CC(CC(=O)O)C(C(=O)O)C(=O)O</smiles>

Fig. 5. Proposed mechanism of propionic acid formation from pyruvate.

There is definite evidence that $\mathrm{CO}_{2}$ was fixed in the propionic acid formed. If the tracer carbon were located solely in the carboxyl group, the $\mathbf{C}^{\mathbf{1 3}}$ excess in the carboxyl should be three times that in the whole molecule; in fact it was not quite three times. This can be explained by a slight mistake in the manipulation of material in the preparation of the barium carbonate; unfortunately the author did not have the opportunity to repeat the experiment. Despite these inaccuracies the results indicate that no $\mathrm{CO}_{2}$ was fixed in the acetic acid and that it was fixed in the carboxyl group of propionic acid.

The ratio propionic acid:acetic acid in the fermentation carried out under 
pressure with sodium carbonate added was $1 \cdot 9: 1$, whereas the control tube without carbonate and not under pressure was 1·19:1. All the lactate was fermented in each case. This confirms, in a growth experiment, the results already obtained with washed suspensions, namely, that the amount of propionic acid formed is dependent on the amount of $\mathrm{CO}_{2}$ present.

\section{DISCUSSION}

The scheme set out in Fig. 5 appears to be supported for Veillonella by the following evidence: (a) During the fermentation of lactic acid, $\mathrm{CO}_{2}$ is fixed in the carboxyl group of propionic acid. (b) All the postulated intermediates are attacked by the bacteria. (c) The occurrence of the reversible reactions from pyruvic acid to succinic acid are well established in other micro-organisms (Krebs, 1943) and in animal tissues (Utter \& Wood, 1945). (d) Fermentation of lactate by washed suspensions of Veillonella did not take place in the absence of $\mathrm{CO}_{2}$. (e) The amount of propionic acid formed depended on the $\mathrm{CO}_{2}$ concentration in the medium. From the nature of the experimental conditions it was not possible to state whether all the propionic acid arose from $\mathrm{CO}_{2}$ fixation. $(f)$ Only bacteria which were grown on D-tartrate attacked this compound in washed suspension. The dicarboxylic acids of very similar structure, oxaloacetate, L-malate, fumarate and succinate, were fermented by bacteria grown on lactate or D-tartrate. This indicated that the enzymes which attack the postulated intermediates in the formation of propionic acid are truly constitutive, whereas those responsible for the primary breakdown of D-tartrate are adaptive. The fact that bacteria grown on $\mathbf{D}$-tartrate did not attack lactate, shows that no propionate is formed by the direct reduction of lactate, confirming the findings of Barker \& Lipmann (1944) in sodium fluoride inhibition studies with Propionibacterium pentosaceum.

Two mechanisms of hydrogen formation have been established with microorganisms: (a) bacteria of the coli-aerogenes group form hydrogen by the decomposition of formate (Stephenson \& Stickland, 1932, 1933; Kalnitsky \& Werkman, 1943); (b) Koepsell, Johnson \& Meek (1944) have shown that Clostridium butylicum will convert pyruvate anaerobically to acetic acid, $\mathrm{CO}_{2}$ and $\mathrm{H}_{2}$, formic acid not being an intermedate in this reaction.

With Veillonella it is thought that hydrogen production takes place by method $(b)$ since it was shown that: (1) the bacteria do not attack formate; (2) in the fermentation of pyruvate, acetic acid, $\mathrm{CO}_{2}$ and $\mathrm{H}_{2}$ were formed in approximately equal quantities (Table 2); (3) the fermentation of L-malate and fumarate produced equal amounts of hydrogen and acetic acid. These findings seem to fit well with the idea that $\mathrm{CO}_{2}, \mathrm{H}_{2}$ and acetic acid arise in equimolar proportions from pyruvate as precursor. However, contrary to the findings of Kubowitz (1934) with Clostridium butylicum and of Cardon \& Barker (1946) with Diplococcus glycinophilus, it was found that an atmosphere of hydrogen had no effect on the amount of hydrogen produced by Veillonella from pyruvate.

In addition to the formation of acetic acid from pyruvic acid it has been claimed that a direct splitting of succinic acid into two molecules of acetic acid can take place (Slade \& Werkman, 1943). There seems to be no question of 
acetic acid being formed by this method in the present instance, for when succinic acid was attacked in washed suspensions only propionic acid and $\mathrm{CO}_{2}$ were formed, and in the $\mathrm{CO}_{2}$ fixation experiments significant amounts of isotopic carbon were not found in the acetic acid formed from the fermentation of lactate. If acetic acid had arisen from succinic acid, carboxyl-labelled acetic acid would have been expected to appear.

The fermentation of tartrate by bacteria has been little studied. Barker (1936) studied the fermentation of tartaric, fumaric and L-malic acids by Aerobacter aerogenes and found that they give rise to the same products as glucose. The probable course of the reaction is via oxaloacetic acid followed by decarboxylation to $\mathrm{CO}_{2}$ and pyruvic acid (Stephenson, 1939). Propionic acid would be formed via L-malic, fumaric and succinic acids.

The anabolic (biosynthetic) process from pyruvate to carbohydrate has usually been conceived as the reverse of the catabolic process. This involves the production of phosphorylated derivatives of glucose, and the question arises, why is it that glucose is not fermented by some bacteria such as Veillonella? The so-called 'direct' fermentation of disaccharides also appears to be related to this problem. Pelczar \& Doetsch (1949), when isolating and identifying bacteria of the genus Neisseria from the nasopharynx of humans, encountered several strains which fermented maltose with acid production while glucose was not fermented. It seems that in both cases the enzyme necessary to carry out the primary phosphorylation of the glucose may be missing.

My thanks are due to Dr S. R. Elsden and Dr R. Scarisbrick, for their interest and advice throughout this work, and to the late Dr Marjory Stephenson and Dr E. F. Gale for many useful discussions. My thanks are also due to Dr A. S. Macfarlane of the National Institute of Medical Research, Mill Hill, for the KCN enriched with $\mathrm{C}^{13}$ and to Mr Palmer of the Atomic Energy Research Establishment for carrying out the $\mathrm{C}^{13}$ assays.

\section{REFERENCES}

Barker, H. A. (1936). Fermentation of some dibasic $C_{4}$ acids by Aerobacter aerogenes. Proc. Acad. Sci. Amst. 39, 1.

BARKER, H. A. \& LipMANN, F. (1944). On lactic acid metabolism in propionic acid bacteria and the problem of oxido-reduction in the system fatty-hydroxy-keto acid. Arch. Biochem. 4, 361.

BARKER, H. A. \& WiKÉN, I. (1948). The origin of butyric acid in fermentation of threonine by Clostridium propionicum. Arch. Biochem. 17, 165.

Cardon, B. P. \& Barker, H. A. (1947). Amino acid fermentations by Clostridium propionicum and Diplococcus glycinophilus. Arch. Biochem. 12, 165.

Carson, S. F. \& Ruben, S. (1940). Carbon dioxide assimilation by propionic acid bacteria studied by the use of radioactive carbon. Proc. nat. Acad. Sci., Wash., 26, 422.

Carson, S. F., Foster, J. W., Ruben, S. \& Barker, H. A. (1941). Radioactive carbon as an indicator of carbon dioxide utilization. V. Propionic acid bacteria. Proc. nat. Acad. Sci., Wash., 27, 229.

ELSDEN, S. R. (1938). The effect of $\mathrm{CO}_{2}$ on the production of succinic acid by Bact. coli commune. Biochem. J. $32,187$.

Gale, E. F.(1946). The bacterial amino-acid decarboxylases. Advances in Enzymology, $6,1$. 
JoHns, A. T. (1949). The mechanism of propionic acid formation in bacterial fermentations. Nature, Lond., 164, 620.

JoHns, A. T. (1951). Isolation of a propionic acid producing bacterium from the rumen of sheep. J. gen. Microbiol. 5, 317.

Johnson, M. J., Peterson, W. H. \& Fred, E. B. (1931). Oxidation and reduction relations between substrate and products in the acetone-butyl alcohol fermentation. J. biol. Chem. 91, 569.

Kalnitsky, G. \& Werkman, C. H. (1943). The anaerobic dissimilation of pyruvate by a cell-free extract of Esch. coli. Arch. Biochem. 2, 113.

Koepsell, H. J., Johnson, M. J. \& Meek, J. S. (1944). Role of phosphate in pyruvic acid dissimilation by cell-free extracts of Clostridium butylicum. J. biol. Chem. 154, 535.

Krampitz, O., Wood, H. G. \& Werkman, C. H. (1943). Enzymatic fixation of carbon dioxide in oxalacetate. J. biol. Chem. 147, 243.

Krebs, H. A. \& Johnston, W. A. (1937). Metabolism of ketonic acids in animal tissues. Biochem. J. 31, 645.

Krebs, H. A. (1943). Carbon dioxide assimilation in heterotrophic organisms. Ann. Rev. Biochem. 12, 529.

Krebs, H. A. \& Eggleston, L. V. (1941). Biological synthesis of oxalacetic acid from pyruvic acid and carbon dioxide. 2. The mechanism of carbon dioxide fixation in propionic bacteria. Biochem. J. 35, 676.

Kuвowitz, F. (1934). Ueber die Hemmung der Buttersäuregärung durch Kohlenoxyd. Biochem. Z. 274, 285.

Pelczar, M. J. \& Doetsch, R. N. (1949). On the direct fermentation of maltose. Science, 110, 265.

Slade, H. D. \& Werkman, C. H. (1943). Assimilation of acetic and succinic acids containing heavy carbon by Aerobacter indologenes. Arch. Biochem. 2, 97.

Stephenson, M. \& Strickiand, L. H. (1932). Hydrogenlyases, bacterial enzymes liberating molecular hydrogen. Biochem. J. 26, 712 .

Stephenson, M. \& Strickland, L. H. (1933). Hydrogenlyases. III. Further experiments on the formation of formic hydrogenlyases by Bact. coli. Biochem. J. 27, 1528.

Stephenson, M. (1939). Bacterial Metabolism, 2nd ed. London: Longmans, Green and Co.

UTter, M. F. \& Wood, H. G. (1945). Fixation of $\mathrm{CO}_{2}$ in oxalacetate by pigeon liver. J. biol. Chem. 160, 375.

Werkman, C. H. \& Wood, H. G. (1942). Heterotrophic assimilation of carbon dioxide. Advanc. Enzymol. $2,135$.

Westerkamp, H. (1933). Keto acids in blood and serum. Biochem. Z. 263, 239.

Wood, H. G. \& Werkman, C. H. (1940). The relationship of bacterial utilisation of $\mathrm{CO}_{2}$ to succinic acid formation. Biochem. J. 34, 129.

Wood, H. G., Werkman, C. H., Hemingway, A. \& Nier, A. O. (1940). Heavy carbon as a tracer in bacterial fixation of carbon dioxide. J. biol. Chem. 135, 789.

Wood, H. G., Werkman, C. H., Hemingway, A. \& Nier, A. O. (1941). Heavy carbon as a tracer in heterotrophic carbon dioxide assimilation. J. biol. Chem. 139, 365 .

Wood, H. G., Werkman, C. H., Hemingway, A., Nier, A. O. \& Stuckwisch, C. G. (1941). Reliability of reactions used to locate assimilated carbon in propionic acid. J. Amer. chem. Soc. 63, 2140.

Woods, D. D. \& Clifton, C. E. (1937). Studies in metabolism of strict anaerobes (genus Clostridium). VI. Hydrogen production and amino-acid utllisation by Clostridium tetanomorphum. Biochem. J. 31, 1774.

(Received 4 January 1950) 